\title{
TOWARDS A 3D SPATIAL URBAN ENERGY MODELLING APPROACH
}

\author{
J.-M. Bahu*, A. Koch, E. Kremers, S.M. Murshed
}

European Institute for Energy Research - EIFER, Energy Planning and Geosimulation, 76131 Karlsruhe, Germany (bahu, koch, kremers, murshed)@eifer.org

KEY WORDS: 3D city model, urban planning, heat energy demand, energy systems, Agent-Based Modelling.

\begin{abstract}
:
Today's needs to reduce the environmental impact of energy use impose dramatic changes for energy infrastructure and existing demand patterns (e.g. buildings) corresponding to their specific context. In addition, future energy systems are expected to integrate a considerable share of fluctuating power sources and equally a high share of distributed generation of electricity. Energy system models capable of describing such future systems and allowing the simulation of the impact of these developments thus require a spatial representation in order to reflect the local context and the boundary conditions.

This paper describes two recent research approaches developed at EIFER in the fields of (a) geo-localised simulation of heat energy demand in cities based on 3D morphological data and (b) spatially explicit Agent-Based Models (ABM) for the simulation of smart grids. 3D city models were used to assess solar potential and heat energy demand of residential buildings which enable cities to target the building refurbishment potentials. Distributed energy systems require innovative modelling techniques where individual components are represented and can interact. With this approach, several smart grid demonstrators were simulated, where heterogeneous models are spatially represented.

Coupling 3D geodata with energy system ABMs holds different advantages for both approaches. On one hand, energy system models can be enhanced with high resolution data from 3D city models and their semantic relations. Furthermore, they allow for spatial analysis and visualisation of the results, with emphasis on spatially and structurally correlations among the different layers (e.g. infrastructure, buildings, administrative zones) to provide an integrated approach. On the other hand, 3D models can benefit from more detailed system description of energy infrastructure, representing dynamic phenomena and high resolution models for energy use at component level. The proposed modelling strategies conceptually and practically integrate urban spatial and energy planning approaches. The combined modelling approach that will be developed based on the described sectorial models holds the potential to represent hybrid energy systems coupling distributed generation of electricity with thermal conversion systems.
\end{abstract}

\section{INTRODUCTION}

Today's needs to reduce the environmental impact of energy use impose dramatic changes for energy infrastructure and existing demand patterns (e.g. buildings) corresponding to their specific context. Heppenstall, Crooks et al. (2012) argue that there is an inherent need to develop robust research approaches to address societal grand challenges such as energy depletion and use as well as climate change. The analysis of the building conditions such as morphology, typology, heating energy demands, etc. at a local level would allow urban planners and decision makers to target building refurbishment potentials.

In addition, future energy systems are expected to integrate a considerable share of fluctuating power sources and equally a high share of distributed generation of electricity. Energy system models capable of describing such future systems and allowing the simulation of the impact of these developments thus require a spatial representation in order to reflect the local context and the boundary conditions.

Furthermore, simulation through an Agent-Based Modelling $(\mathrm{ABM})$ approach allows for representing the dynamic behaviour of the system over time, in which the different entities of the system (called agents) are represented autonomously and interact with a common environment. This approach can be then used to reflect operational strategies as well as decentralised decision making in distributed energy systems by representing the communication between the agents.

In the urban context multiple interacting systems are not only coupled by their spatial proximity but also for functional ways. Intelligent management of resources often pursued in smart city approaches demands for more and more integrated capabilities to model interactions among the various urban resource flows.

The research focus on the spatial aspects of energy modelling for distributed energy system. In general, dynamic models provide insights into the process inherent in the evolution of a system, whereas, Geographic Information System (GIS) provide spatial databases and allow for spatial analysis, interpretation and visualization of data. Combining complex dynamic system modelling (e.g. ABM) and GIS will enable to develop a model that is both dynamic and spatially explicit. The applications and advantages of such models are widely discussed in (Hazelton, Leahy et al., 1992; Despotakis and Giaoutzi, 1996). However, with the increasing maturity of GIS and availability of 2D and 3D granular datasets, 3D GIS has emerged as an essential tool to enhance the dynamic modelling capabilities. The integration of ABM and GIS technology allow developing experimental prototype models for simulating complex spatial systems representing for example urban growth, traffic congestion as well as ecosystems such as bird migration. A detail discussion is available at (Crooks, Hudson-Smith et al., 2010; Heppenstall, Crooks et al., 2012). 
Energy systems today are facing several challenges, due to the profound paradigm change that the sector is undergoing. Some examples to be mentioned are:

- Two-way communication between the building and responsible entity for load balancing

- Control of lighting, heating, cooling, ventilation, IT, and other energy using systems

- Optimized coordination of energy loads, on-site energy generation and energy storage - based on local or central smartness

- Automatic demand response to dynamic pricing or control signals from the grid and impact on urban energy system

Current energy system models are often static and based on linear approaches, which do not take into account the dynamics of the system. However, for many of the points mentioned above, the representation of the interactions and communication flows is essential. In addition, classical engineering tools for power systems are not always linked to the spatial dimension of the system. Availability of matured GIS technology and granular 3D GIS data impose an added value to the modelling of energy systems.

The aim of this paper is to describe two recent research approaches in the fields of geo-localised simulation of thermal energy needs in cities and spatially explicit agent-based smart grid simulation conducted by the authors at the European Institute for Energy Research (EIFER). Several case studies have been described and showed how these two different approaches can be coupled to model an integrated smart energy system by taking advantage of 3D city models. They also signify the benefits of using semantic 3D city models to urban energy planning for cities.

Section 2 describes the research background with a focus on 3D city models and a short review on energy modelling as well as aspects of ABM in the field of energy system. Section 3 and section 4 describe the data, methods and results of heat energy demand assessment and spatially distributed energy systems respectively. A discussion on different aspects of the integration of models, challenges and their improvement possibilities are discussed in section 5. Finally a conclusion with a focus on future research perspective is drawn in section 6 .

\section{RESEARCH BACKGROUNDS}

\subsection{D city models and energy modelling}

Over the last decades, spatial modelling has vastly grown, mainly due to different tools GIS and its capabilities of spatial analysis covering spatial data handling (e.g. topology), storage and management as well as representation. Previously essentially in 2D, the spatial modelling is today able to assess objects in a 3D environment through multi-scale approaches. The growing interest of cities for using such tools encourages standardisation processes like the European INSPIRE (Infrastructure for Spatial Information in the European Community) initiative and the development of interoperable 3D formats (i.e. CityGML) to manage and store 3D spatial data.

By merging geometrical, topological and semantic aspects, OGC (Open Geospatial Consortium) CityGML standard specifications for 3D city models enables various automatized analysis, particularly useful for different applications related to urban sectors (buildings, transport networks, etc.) (Gröger,
Kolbe et al., 2012). They describe 3D city models in five Levels of Detail (LoD): starting from the LoD0 - Digital Terrain Model (DTM), the LoD1 - buildings as extruded footprint, the LoD2 - buildings with roof shapes, the LoD3 - very detailed buildings with facades details, to the LoD4 - interior structures (Figure 1).

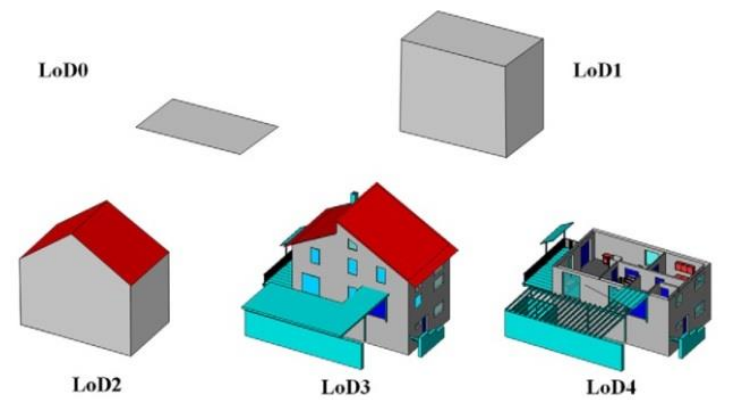

Figure 1: Five Levels of Detail (LoD) in CityGML (Gröger,

Kolbe et al., 2012)

3D city models based on such standards are increasingly used by engineers and urban planners in the environmental and energy sector.

Previously 2D, spatial data was mostly coupled with energy systems based on GIS tools. This coupling between GIS and energy modelling was undertaken by Ratti, Baker et al. (2005), as they proposed a methodology to assess effects of urban texture (e.g. urban geometry) on building energy consumption. Digital Elevation Model (DEM) were analysed (e.g. through the calculation of the surface-to-volume ratio or the selection of the "passive areas") and coupled with the LT model (Baker and Steemers, 2000) in order to provide automatized energy simulations at the neighbourhood scale. The French urbanism research group Atelier Parisien d'Urbanisme (APUR) carried out a study on the crossing of GIS $2.5 \mathrm{D}$ building data with an energy calculation model on the Parisian building stock (APUR, 2007). By merging semantic information of archetypal building classes with morphological building data, they calculated the end energy consumption and the GHG emissions of 96000 Parisian buildings. Later Salat (2009) followed up this study by combining the results with morphological data. Pursuing the previous work of Ratti, Baker et al. (2005), he quantified the impact of different building indicators (e.g. morphology, typology, energy systems, etc.) on energy consumption and $\mathrm{CO}_{2}$ emissions in order to provide some construction recommendations.

With the development of 3D city models, recent studies showed the coupling between 3D data and energy system models. Carrión, Lorenz and Kolbe (2010) proposed a method crossing real heating energy data to a virtual city 3D model. Eicker, Nouvel et al. (2012) developed a model to assess the heat energy demand of residential building from a virtual 3D city model. Based on CityGML, the morphology and topology of 3D data were automatically determined in order to feed energy modelling. Krüger and Kolbe (2012) also developed such a model to assess heat energy demand and implemented it into a semantic 3D city model based on CityGML.

Compared to these methods, our research aims to identify further use of 3D city models in connection with energy system models. Moreover, heat energy demand has been calculated for a large number of Lod2 buildings (17 000 in total) considering building morphology, topology and semantic data. Finally, 
several scenarios relative to the refurbishment of buildings have also been discussed.

\subsection{Agent-based modelling for energy systems}

Energy system modelling and simulation is being mainly influenced by the paradigm shift in the energy sector, which implies a trend towards a more distributed and decentralized system. This trend affects both the production (Distributed Generation) and demand side (Demand Side Management). Especially in cities which have high power densities, distributed technologies can help to decrease transport and distribution losses and allow for less grid congestions due to the simple fact that energy is consumed close to where it is generated. In combination with new Information and Communication Technologies (ICT) adapted to the energy sector such as smart metering or Power Line Communication (PLC), a management of the system at distribution level is being developed, which is commonly known as Smart Grid. This heterogeneous (many different technologies and actors are involved) and dynamic (the management must be flexible and changes over time) system requires for new modelling and simulation approaches.

Agent-based modelling tools are able to capture complex system behaviour such as wanted and unwanted emergent behaviour in these systems, internal and external events, communications within the system, etc. In particular, local effects of the single units comprising the system can be modelled and their effects can be analysed at the system level (Wooldridge, 2009).

Models using the agent-based paradigm are currently state-ofart in a few fields of the energy sector only. In most cases, agents are representations of market actors dealing with the problem of market liberalisation (Sensfuss, Ragwitz et al., 2007). Some agent-based models like Sugarscape by Epstein (2006) show the emergence of counter-intuitive behaviours related to distributed decision-making from heterogeneous agents. These approaches show that the more spatially distributed a system is, the more important it is to take care of local interactions and the differences between agents. In energy systems, the spatial component is essential. We can see this particularly, when taking into account distributed measures, which are applied locally, such as is the case in the smart grid (Kremers, 2012).

For the modelling of energy systems, technical models of the single agents are necessary. Therefore, systems changing over time have to be represented in form of physical and mathematical models of the devices (consumers, producers, etc.). Furthermore, the large amounts of interactions and feedback appearing in distributed energy systems make linear simulation models inappropriate for systemic simulations. Models of this kind have been used to develop control strategies for microgrids, for instance (Dimeas and Hatziargyriou, 2007). In (González de Durana, Barambones et al., 2009), an example of a simple Hybrid Renewable Energy Systems (HRES) is presented and an ABM for such systems, a microgrid, oriented to designing a decentralised supervisory control was developed. At a higher scale, Viejo and Kremers (2009) present a model of the high voltage system at regional scale for an island. The inclusion of simplified technical models in an agent-based framework has been applied in the smart-grid context, where heterogeneous and dynamically changing electrical systems have been simulated in a disaggregated manner (Evora, Kremers et al., 2012). Because agents are defined through their local information, even when being modelled in the same way and with the same objectives, their decision making process can be different among them. This differentiates them from traditional models, where different objects usually share the same inputs.

What characterises energy system simulation models, is that they are indeed dynamic and change over time. Each agent is able to change its internal state according to its needs and objectives. Moreover, the environment is neither static. Changing meteorological variables and human behaviour are only some examples of variable factors. As an electrical energy system has to ensure the balance of production and demand at each point in time, a continuous adaptation is needed. Such a process can be only modelled at a sufficient level of detail using simulation models, which include the capacity to evolve over time.

Seen from the spatial point of view, we have a representation of the objects in the system in three dimensions. Considering their evolution over time can be seen as the fourth dimension, which reflects variable states of a 3D model over time (i.e. 4D).

This paper aims to fill the knowledge gap by integrating agentbased modelling and 4D GIS in order to offer improvements to comprehend complex spatial phenomena. With agent-based models, 4D GIS can represent agent dynamics such as temporal changes in spatial patterns for further time-series analysis of distributed energy systems.

\section{HEAT ENERGY DEMAND MODELLING}

\subsection{Goals}

As it was discussed earlier, EIFER has developed several approaches on energy planning and geo-simulation combining spatial data and energy modelling. Different models based on 3D city models were especially developed, e.g. solar cadastre and PV potential assessment on building roofs, or heating energy demand modelling of residential buildings (Bahu, 2013). This paper discuss the modelling of heat energy demand for a large number of buildings in France to enable cities to target the building refurbishment potentials by providing a rich spatial knowledge of the building stock at the local level, bringing together different building aspects: morphology, typology and energy. Moreover, several scenarios relative to the refurbishment of buildings have also been discussed.

\subsection{D data}

This modelling approach was applied on a sample of $5 \times 5 \mathrm{~km}$ in the $8^{\text {th }}$ arrondissement of Lyon in France. We gathered about 40000 3D LoD2 buildings managed and stored into a geodatabase with the support of ArcGIS (ESRI) and FME (Safe Software). At first, they were overlapped with the cadastre data and then rebuilt in LoD1 in order to avoid several problems related to heterogeneous Building IDs or 3D topology. Consecutive selections (i.e. according to the building function, a minimal height and footprint) led a final sample of 17000 LoD1 residential buildings. Figure 2 describes the total sample of residential buildings according to types and age. 


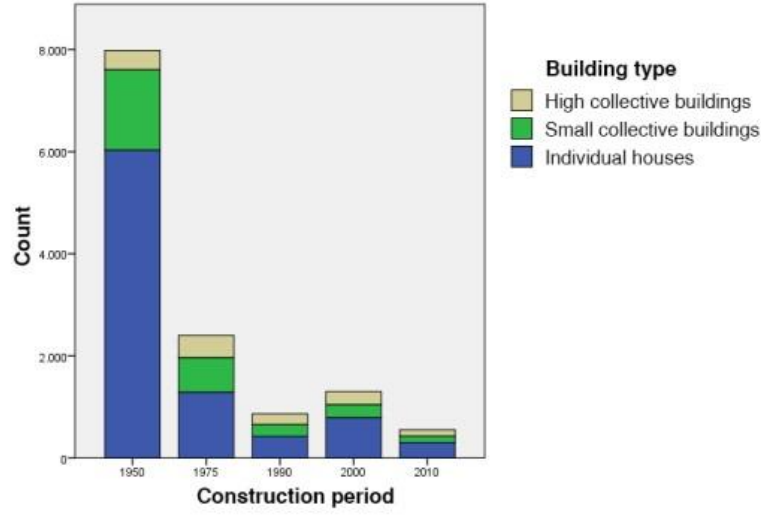

Figure 2: Description of the repartition of building types per building age of the total sample.

\subsection{Methodology}

After gathering semantic data relative to buildings to enrich the 3D city model (building function, age, etc.), a morphological analysis of each building is developed thanks to new urban analysis tools e.g. the 3D GIS. Such tool enables the model to take into account the influence of the urban context on buildings (i.e. building morphology, topology and shared facades or shading effects). The heat demand assessment aims to describe the balance between energy losses (through transmission and ventilation) and energy gains (solar and internal gains). This modelling requires several specific data relative to building structure and efficiency. In order to address the problem associated with data accessibility at the building scale, an archetype engineering approach is undertaken (Swan and Ugursal, 2009). First a detailed local thermal building typology is established, describing the building properties of the main local building classes (U-values, glazing rate, ventilation rate, etc.) based on literature and experts judgement (Pouget, 2011). Then, 3D buildings are classified, in order to link each of them with the previous typology. Solar gains are calculated on each $3 \mathrm{D}$ building based on an annual GIS simulation. The heat energy demand is calculated through an object-oriented simulation based on the official ISO NF 13790 (2004) monthly calculation adapted to the approach.

\subsection{Results}

Finally, the heat energy demand of all 17000 residential buildings was calculated along a year. Two scenarios were considered in order to take into account the renovation state of the buildings:

- Scenario A "construction state": considering all the buildings as non-refurbished

- Scenario B "all refurbished": considering all the buildings as renovated (walls and windows, floor and ceiling) impacting the thermic parameters ( $U$ values and thermal bridges) with typical values from the literature (Institut Wohnen und Umwelt, 2003; Pouget, 2011)
Figure 3 shows the heat energy demand of a part of the sample residential buildings considering the scenario A "construction state".

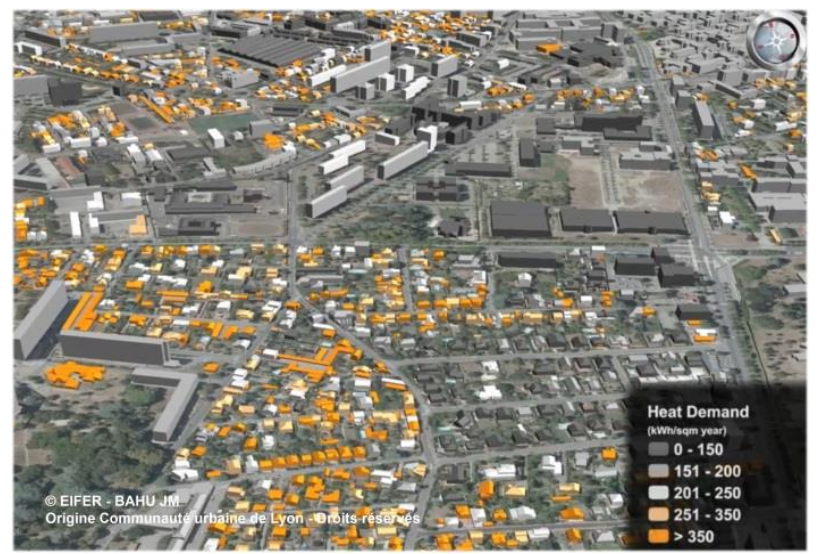

Figure 3: Representation of the heat demand results of residential buildings considering the scenario A "construction state".

Figure 4 and Figure 5 describe the distribution of heat energy demand for all the residential buildings resulting from the scenario A. Figure 6 describes the same for scenario B.

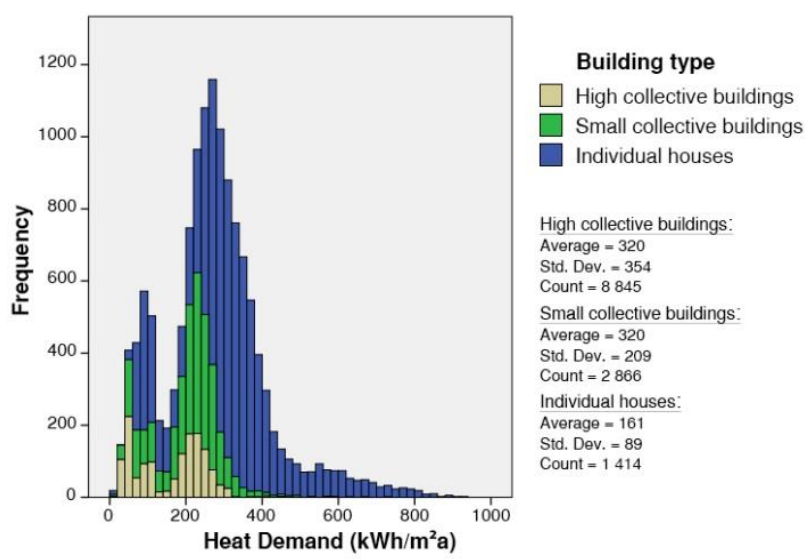

Figure 4: Distribution of the heat energy demand per building type considering the scenario A "construction state".

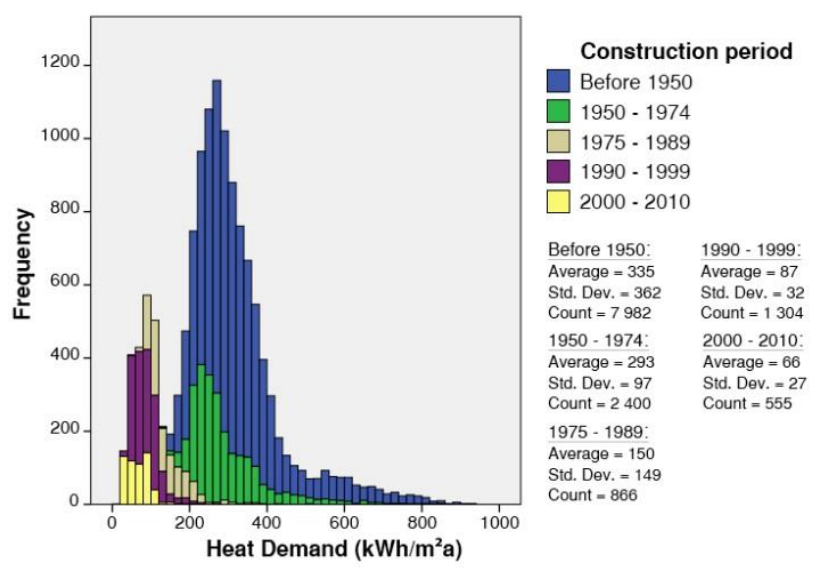

Figure 5: Distribution of the heat energy demand per construction age considering the scenario A "construction state". 


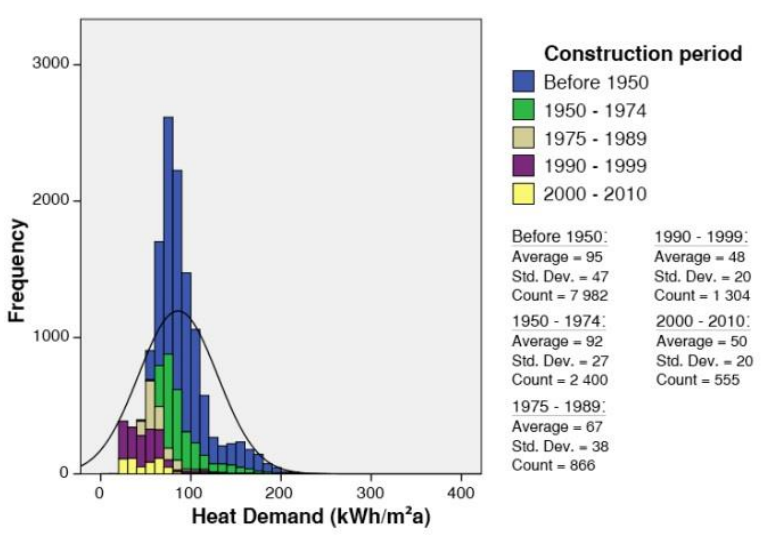

Figure 6: Distribution of the heat energy demand per construction considering the scenario B "all refurbished".

By comparing these results, we noticed a significant difference between the distributions of both scenarios. In the scenario A, heat energy demand of old buildings has an higher average and is more spread out than more recent buildings. In the scenario $\mathrm{B}$, the global distribution is more homogeneous and follows mostly a normal trend (Figure 6). The global average in the scenario A $\left(279 \mathrm{kWh} / \mathrm{m}^{2} \mathrm{a}\right)$ is higher than in the scenario B $(86$ $\mathrm{kWh} / \mathrm{m}^{2} \mathrm{a}$ ). It shows that the refurbishment clearly causes a reduction of $70 \%$ of the total heat energy demand of the residential building stock.

Moreover, these results represent a statistically relevant building sample with 17000 buildings assessed, which proposes more significant results at the urban scale. That is not the case at a smaller urban scale (e.g. a small neighbourhood). By integrating the local dimension in the whole process (i.e. by taking into account the urban morphology and climate, a local building typology or local data), this modelling is also well adapted to specific characteristics of cities.

Because of lacks of accurate real measured consumption data at such a large scale, it wasn't yet possible to calibrate these results with real energy data. Nevertheless, previous inter model calibration tests on several selected buildings, based on validated building energy calculation tools developed by the building research department of EDF in France, showed acceptable results (less than $5 \%$ difference on a sample of 12 test buildings).

Therefore, it can be concluded that by feeding spatial data into energy modelling on large sample of data, this method signifies the benefits of semantic 3D city models to urban energy planning for cities.

\section{CASE STUDIES FOR SPATIALLY DISTRIBUTED ENERGY SYSTEMS}

\subsection{Goals}

As introduced before, agent-based models have already shown their application interest in the energy system field. In this section, some case studies are presented which serve as a base to start the discussion on their interest for and with 3D GIS. These case studies were developed to show the impact of new, distributed and more or less decentralised solutions on an integrated energy system, taking into account a heterogeneous configuration.

\subsection{Methodology}

In the smart grid context, different demonstration projects were modelled at EIFER using a complex systems approach, in which the individual components of the system are represented and can interact $(\mathrm{ABM})$. The models allow simulating the system as a virtual demonstrator, where measures on the system can be tested virtually without any danger to a real system. Due to its disaggregated approach, these models can be spatially represented (geo-localisation) and benefit from a 3D spatial environment. Furthermore, this disaggregated representation of the system allows representing it in a multi-scale way (see Figure 7), both from topological or structural aspects (such as the voltage level or the topology of the power grid) and from different spatial scales (building, district, urban area, region, etc.). Current models usually only consider interactions between elements of the same scale. However, using this approach, it is intended to include cross-scale interactions, which can represent dynamic effects in the system, such as feedback loops, crossing over different scales.

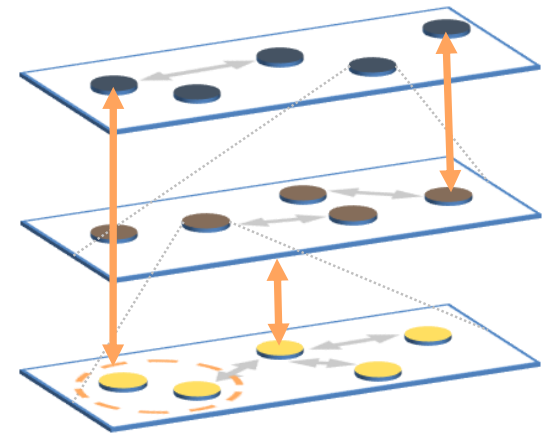

Figure 7: Multi-scale model with cross-scale interactions. Entities at same (grey) but also between different levels (orange) can exchange information and interact.

Detailed data is a fundamental requirement for agent-based models. These models represent a high resolution which, in contrast to 3D GIS applications, is not typical in the domain of energy system modelling. Using 3D as a basis to literally "feed" agent-based energy system models allows parameterising the different agents with their local information, according to the available data. 3D data can be used to enhance the performance of the simplified technical models within the agents, for example buildings, which can make use of geometrical and environmental data.

\subsection{Application examples and results}

To analyse the behaviour of smart grid measures, for example demand side management (DSM), in which the demand is adapted to changing dynamics of the power grid (in contrast to the traditional approach where only the production is controllable), different case studies have been modelled. In the French context, it is common to use electrical heating systems. These can be remotely controlled and disconnected (load shedding) for some time, without affecting the comfort of the client, due to thermal building inertia. 

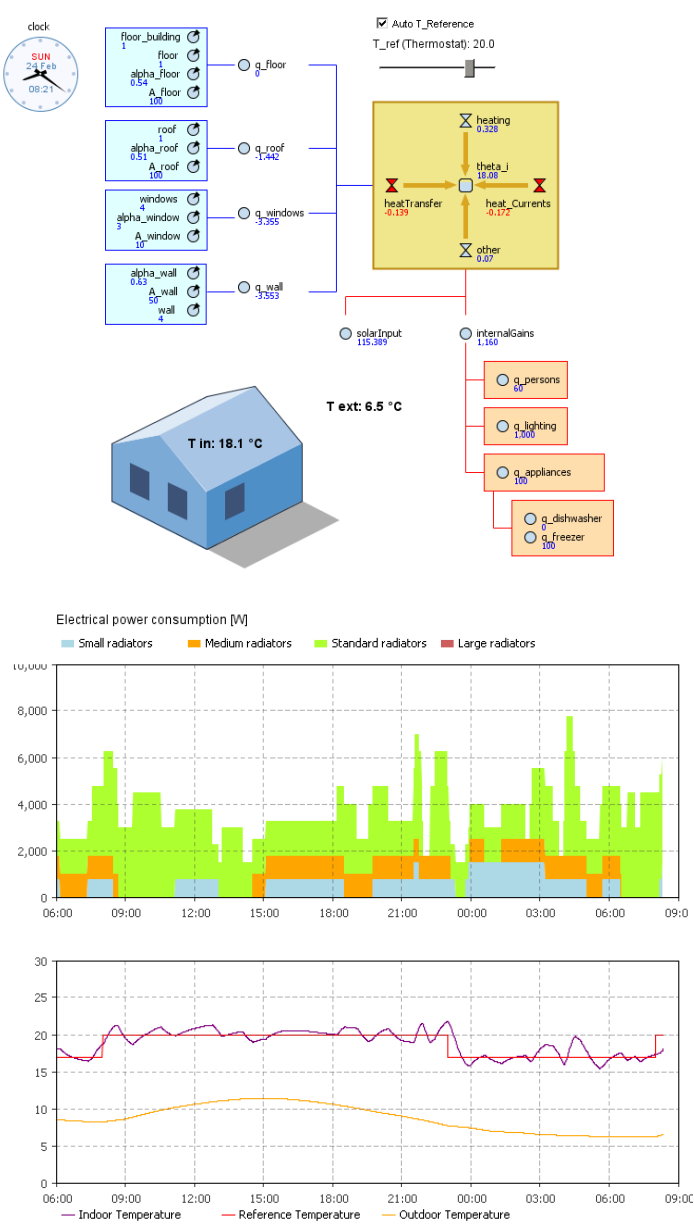

Figure 8: Simplified one-zone building model for electrical heating

A simplified model for the thermal behaviour of a building was developed (Figure 8) which calculates the temperature in function of the thermal gains that are injected or removed from the building. Inside the building, an electrical heating system is represented which controls the temperature and maintains a setpoint. The electrical heating model produces an electrical consumption which is used to compute its load curve.

This simplified thermal behaviour model can be embedded in a building agent, and replicated for every building in a urban zone. In a first stage, and to analyse technical constraints, this is done without a concrete localisation in space, and not taking into account possible network topologies. The tool used for the implementation is Anylogic which is a multi-purpose simulation environment allowing for different modelling methods.

Then, the agent is parameterised using the local information from the 3D model, using the volume, shape, orientation or type of the building. In this case, we have the same energy model in each building, but are running it in a massively replicated manner, with different local parameter sets for each building. Moreover, thermal exchanges between adjacent buildings can be included, representing a highly complex interacting system. Using such an approach, not only the local effects are represented, but the emergence of systemic phenomena is allowed, such as the appearance of local heat islands.

Once modelled the system in this way, different heating technologies can be added as agents acting on the temperature inside the building. Furthermore, they can be linked through their respective carrier network (power lines, heat networks, etc.), which can be spatially located through 3D models (see Figure 9).

In the MILLENER project ${ }^{*}$, a model for large scale simulation of energy system was created, allowing for the simulation of the electrical behaviour of more than 100000 building agents. The model takes historical data of consumption at an aggregated level as input. This consumption is broken down using local parameters until building level. Each building includes unitary models for different appliances, like air-conditioning or heating. These appliances modify the individual load curve, based on their behaviour. This disaggregated system can be managed through different strategies, and the model allows extracting the impact of these different strategies at multiple levels and through different aggregation methods. For example, the impact on the energy system itself can be evaluated as the topology of the network is included in the model. Also, regional evaluations by administrative zones can be extracted. The model was developed in TAFAT (Evora, Kremers et al., 2012), a tool which allows massive agent based simulations. This tool is currently being developed in cooperation with the University of Las Palmas de Gran Canaria/SIANI.

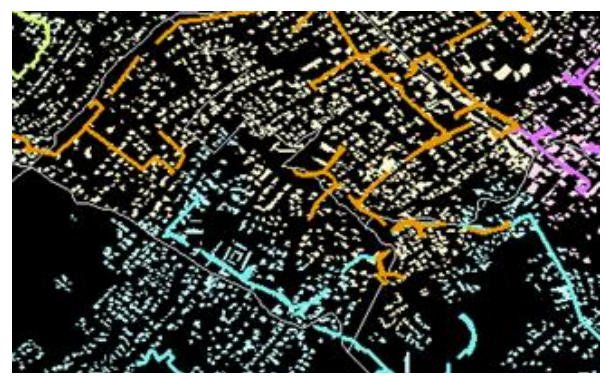

Figure 9: Example of relating building agents and electrical lines (from GIS). Building agents are geo-referenced and connected by proximity to the closest infrastructure line (same colours).

\section{DISCUSSION}

The coupling of 3D geodata with energy system models involves mutual benefits. Crooks, Hudson-Smith et al. (2010) describes that several ABM has been performed in 3D environment (as simulation background), with a sense of place for agents in 2D. The modelling is mostly aimed as visualisation in $3 \mathrm{D}$ space, with a loose coupling of model and 2D data. However, we have shown that 3D city models can be embedded not only by allowing 3D spatial data for improved models but also by allowing analysis and visualisation of results. With the increasing computation power of PCs, combining of 3D city model and $\mathrm{ABM}$ allow modelling smart energy system for a whole city.

Some ABM modelling tools are capable of handling 2D and 3D data $^{* *}$.On the other hand, desktop based GIS software e.g. ESRI ArcGIS is currently developing an integrated ABM framework (Agent Analyst) within the ArcGIS (Johnston, 2013). There is hardly any model focusing directly on energy-related issues and

\footnotetext{
${ }^{*}$ http://sei.edf.com/actualites/le-projet-millener/pourquoimillener-y-83904.html

** http://en.wikipedia.org/wiki/Comparison of agentbased modeling software
} 
3D GIS, but many models show the feasibility of the approach and its interest in field like transport, logistics, etc. (discussed in section 1). Furthermore, in some of the agent-based modelling of energy systems, GIS and 2D GIS data is already used as an input, and tools in this field (Repast, Anylogic, Netlogo) allow for the integration of 2D GIS already (Crooks and Castle, 2012).

The trend in disaggregation, both in data representation for GIS and especially urban systems, as well as in the engineering modelling domain to tackle more and more complex systems inherently suggests a coupling at a higher level of detail.

Virtual 3D city models are particularly relevant for modelling of distributed energy systems. The heat demand assessment model previously presented is a good example of it.

The coupling of $\mathrm{ABM}$ and $3 \mathrm{D}$ city model imposes several problems such as data management, interoperability, interface and efficient software tools. 3D city models are summing up geo-localised semantic data on the city. As it was discussed in the previous heat demand model, the building age and function are stored in attributes of 3D Buildings which help further analyses to enrich the information and adapt to specific needs, e.g. the analysis of objects morphology (width of streets, volume of buildings, etc.). More advanced analysis are also possible like the topological assessment, which is very useful for taking into account the urban form (Ghawana and Zlatanova, 2010). The richness of semantic 3D city models allows feeding energy models, which often require a large amount of granular data originates from different domains. 3D city models are combining today more and more efficient geo-database management extensions in order to address the problems associated with data management. For example, recently, Breunig et al (2013) proposes a 3D geodatabase framework (DB4GeO) for supporting complex 3D/4D mass data and visualisation using WebGL 3D interface.

An interoperable format (e.g. CityGML) enables the combination of other tools for further analyses, e.g. statistical tools like the classification process in the previous model and the location of local typologies in GIS or energy models. Semantic 3D city model are then a good and flexible base for coupling and implementing further modelling approaches, e.g. micro-climatic simulation.

Amouroux (2009) developed a open source platform (GAMA) where 2D GIS and Agent based models can be simulated. 3D city models also provide an efficient interface for users and modellers who are then able to visualise, access, analyse, modify and finally enrich the data. They create a real addedvalue to the provided results. High resolution, adaptation to different LoDs, flexibility and access to the data by using innovative interactive technologies provide meaningful representation for the end-user.

As we have previously seen in the section $4,3 \mathrm{D}$ city models can benefit from more detailed system models of energy infrastructure, representing dynamic phenomena and high resolution models for energy use at individual levels. The proposed modelling strategies are seen as a means to integrate urban spatial and energy planning approaches both at a conceptual as well as on a practical level. However, there are still some barriers which require further research. As the different topics are usually treated by different experts groups (geographers, engineers, urban planners, etc.), an interdisciplinary exchange of research is important to assure an integrated approach.

\section{CONCLUSION AND OUTLOOK}

This paper describes two recent research approaches for geolocalised simulation of heat energy demand in cities based on $3 \mathrm{D}$ morphological data and spatially explicit ABM for the simulation of smart grids. Several case studies have been described in which both approaches have been separately applied. Coupling of the two approaches holds the potential to further use the spatial representation of $3 \mathrm{D}$ city models in connection with highly disaggregated energy system models. Buildings in different aggregation states can thus operate as the focal point for modelling energy flows within cities. The agentbased simulation approach described further enables the representation of behaviour of users or technical sub-systems and their interactions among themselves and the environment. For example, the demand side of the ABM can be enriched by coupling heat energy demand modelling outputs and building refurbishment scenarios. In this way, the level of comprehensiveness of simulation will be much increased.

The proposed modelling can improve urban energy modelling, especially with regard to a more and more integrated energy system in which different technologies link thermal and electric needs with local generation, distribution and consumptions (Figure 10). Examples of such hybrid systems are described in the framework of the IEA DSM program (Kärkkäinen, 2008).

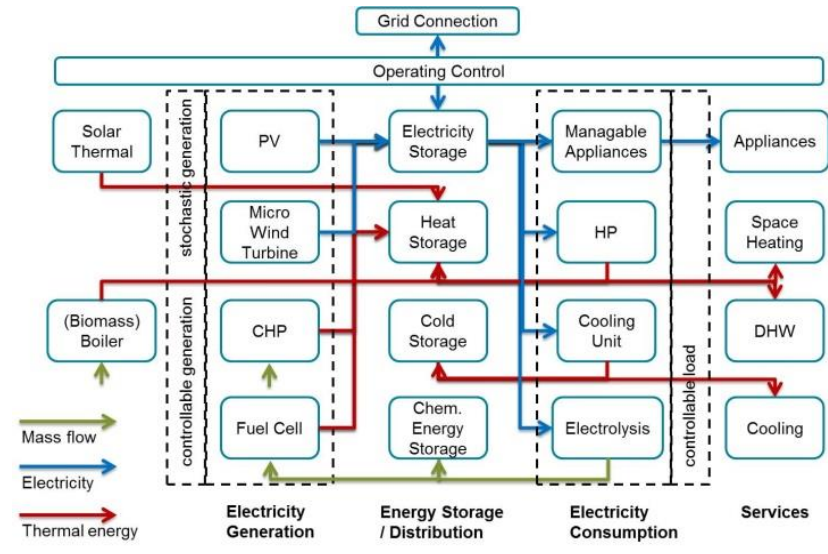

Figure 10: Examples of smart urban energy systems

Linking a dynamic system (e.g. ABM) and 3D city models, 4D GIS enables representation of agent dynamics such as temporal changes in spatial patterns for further time-series analysis of distributed energy systems. This is highly relevant for future simulation of hybrid energy systems because building simulation typically ranges from calculation steps between hours and month for the thermal energy needs, while the representation of electrical systems requires a much higher temporal resolution.

The integration of these different types of models having different spatial and temporal levels of aggregations, of static or dynamic types in nature holds great possibilities to enrich ABM. In this way, an integrated smart energy system can be built by taking advantage of $3 \mathrm{D}$ city models.

For an efficient energy planning cities will have to search for solutions capable of structuring and making available manifold and diverse data sources and formats. One possible solution is the semantic 3D data model for urban areas. Here any kind of collected, measured or simulated data can be integrated into a common structure. Two simulation approaches that can provide for a basis for urban energy planning have been discussed in 
this paper. Their integration is seen as a first step to provide an energy system model for simulation the impacts of an integrated system to assess energy needs in buildings as well as electricity supply and demand structure. Future prospects include the representation of essential infrastructure to describe impacts of a connected operation of different de-centralised energy conversion systems.

\section{REFERENCES}

2004. NF EN ISO 13790: 2004-11, Performance thermique des bâtiments : Calcul des besoins d'énergie pour le chauffage des locaux: AFNOR Editions: 65.

Amouroux, E., Chu T. Q., Boucher A., et al., 2009. GAMA: an environment for implementing and running spatially explicit multi-agent simulations. Agent computing and multi-agent systems. A. K. Ghose. Berlin Heidelberg., Springer: 359-371.

Apur, 2007. Consommations d'énergie et émission de gaz à effet de serre liées au chauffage des résidences principales parisiennes: APUR: 48.

Bahu, J.-M., 2013. Applied Energy Geo-Simulation for Cities from 3D Urban Data. Chancen der Energiewende : wissenschaftliche Beiträge des KIT zur 1. Jahrestagung des KIT-Zentrums Energie, Karlsruhe, KIT Scientific Publishing, Karlsruhe

Baker, N. and Steemers K., 2000. Energy and environment in architecture: a technical design guide. Taylor \& Francis.

Breunig, M., Butwilowski E., Golovko D., et al., 2013. Advancing DB4GeO. Progress and New Trends in $3 D$ Geoinformation Sciences. J. Pouliot, S. Daniel, F. Hubert and A. Zamyadi. Berlin Heidelberg, Springer 193-210.

Carrión, D., Lorenz A. and Kolbe T. H., 2010. Estimation of the energetic rehabilitation state of buildings for the city of Berlin using a 3D city model represented in CityGML. ISPRS Conference: International Conference on 3D Geoinformation. XXXVIII-4.

Crooks, A. T. and Castle C. J. E., 2012. The Integration of Agent-Based Modelling and Geographical Information for Geospatial Simulation. Agent-Based Models of Geographical Systems. Alison J. Heppenstall, Andrew T. Crooks, Linda M. See and M. Batty. Dordrecht Heidelberg London New York, Springer 746.

Crooks, A. T., Hudson-Smith A. and Patel A., 2010. Building 3D Agent-Based Models for Urban Systems: University College London; London. Paper 161 - 2010: 35.

Despotakis, V. K. and Giaoutzi M., 1996. Spatial Modeling of Urban Dynamics; Cambridge, MA.

Dimeas, A. L. and Hatziargyriou N. D., 2007. Agent based control of Virtual Power Plants. Intelligent Systems Applications to Power Systems (ISAP).

Eicker, U., Nouvel R., Schulte C., et al., 2012. 3D-Stadtmodelle für die wärmebedarfberechnung. BauSIM 2012: 7.
Epstein, J. M., 2006. Generative social science: Studies in agent-based computational modeling. Princeton Univ Pr.

Evora, J., Kremers E., Hernandez M., et al., 2012. A large-scale electrical grid simulation for massive integration of distributed photovoltaic energy sources. 6th European Conference on PVHybrids and Mini-Grids (OTTI), Chambéry, France.

Ghawana, T. and Zlatanova S., 2010. Data consistency checks for building a 3D model: A case study of Technical University, Delft Campus, The Netherlands. Geospatial World Vol. 4.

González De Durana, J. M., Barambones O., Kremers E., et al., 2009. Complete Agent based Simulation of Mini-Grids. The Ninth IASTED European Conference on Power and Engineering Systems, EuroPES 2009, Palma de Mallorca, Spain, Acta Press.

Gröger, G., Kolbe T. H., Nagel C., et al., 2012. OGC City Geography Markup Language (CityGML) Encoding Standard, Version 2.0.0. Open Geospatial Consortium Inc.(OGC Doc. No. 12-019).

Hazelton, N. W. J., Leahy F. J. and Williamson I. P., 1992. Integrating dynamic modeling and geographic information systems. Urban and Regional Information Systems Association 4: $47-58$.

Heppenstall, A., J., Crooks A. T., Batty M., et al., 2012. Reflections and Conclusions: Geographical Models to Address Grand Challenges. Agent-Based Models of Geographical Systems. A. J. Heppenstall, A. T. Crooks, L. M. See and M. Batty. Dordrecht Heidelberg London New York, Springer: 739747.

Heppenstall, A. J., Crooks A. T., See L. M., et al., Eds., 2012. Agent-Based Models of Geographical Systems. Dordrecht Heidelberg London New York, Springer

Institut Wohnen Und Umwelt, I., 2003. Deutsche Gebäudetypologie - Systematik und Datensätze: 9.

Johnston, K. M., 2013. Agent Analyst Agent-Based Modeling in ArcGIS. ESRI Press, Redlands, California.

Kärkkäinen, S., 2008. Task XVII Integration of Demand Side Management, Distributed Generation, Renewable Energy Sources and Energy Storages - State of the art report Vol 1.

Kremers, E., 2012. Modelling and Simulation of Electrical Energy Systems through a Complex Systems Approach using Agent-Based Models: Universidad del País Vasco - Euskal Herriko Unibertsitatea; Vitoria-Gasteiz. PhD: 178.

Krüger, A. and Kolbe T. H., 2012. Building analysis for urban energy planning using key indicators on virtual 3D city models - The energy atlas of Berlin. Int. Arch. Photogramm. Remote Sens. Spatial Inf. Sci. XXXIX-B2: 145-150.

Pouget, A., 2011. Amélioration thermique des bâtiments collectifs construits de 1850 à 1974: Le guide ABC. Parisiennes.

Ratti, C., Baker N. and Steemers K., 2005. Energy consumption and urban texture. Energy and Buildings 37(7): 762-776. 
ISPRS Annals of the Photogrammetry, Remote Sensing and Spatial Information Sciences, Volume II-2/W1, ISPRS 8th 3DGeolnfo Conference \& WG II/2 Workshop, 27 - 29 November 2013, Istanbul, Turkey

Salat, S., 2009. Energy loads, CO2 emissions and building stocks: morphologies, typologies, energy systems and behaviour. Building Research \& Information 37(5-6): 598-609.

Sensfuss, F., Ragwitz M., Genoese M., et al., 2007. Agentbased Simulation of Electricity Markets - A Literature Review.: Fraunhofer ISI; Karlsruhe: 38.

Swan, L. G. and Ugursal V. I., 2009. Modeling of end-use energy consumption in the residential sector: A review of modeling techniques. Renewable and Sustainable Energy Reviews 13(8): 1819-1835.

Viejo, P. and Kremers E., 2009. Simulation of energy system scenarios for regional planning decision-making using agentbased modeling. 11th International Conference on Computers in Urban Planning and Urban Management CUPUM, Hong Kong.

Wooldridge, M. J., 2009. An introduction to multiagent systems. Wiley, Chichester, West Sussex, United Kingdom.

\section{AKNOWLEDGMENTS}

A large part of the methodological basis presented in the different case studies was developed in the context of research projects funded by EDF. The authors would like to express special thanks to EDF and the colleagues of the research and development departments involved in the exchange. 